\title{
CROSS-SHORE TRANSPORT ON GRAVEL BEACHES
}

\author{
Betsy S. Hicks ${ }^{1}$, Nobuhisa Kobayashi, Jack A. Puleo, and Ali Farhadzadeh
}

\begin{abstract}
A numerical and experimental investigation of profile evolution was completed on a laboratory gravel beach. A total of four tests were completed on a gravel beach constructed in a small-scale wave flume, with different incident wave conditions and initial beach slopes. The tests allowed for an examination of erosional, accretional, and migratory bar conditions as well as how the differences affected the final quasi-equilibrium profiles. Profile evolution and hydrodynamic data were collected for comparison with the time- and depth- averaged numerical model CSHORE. The numerical formulations developed for damage progression on a stone armor layer were found to predict the profile evolution on the steeper test conditions but required modifications to the bedload formula to better predict the accretional and bar migration tests.
\end{abstract}

Keywords: gravel beach; profile evolution; bed load; numerical model

\section{INTRODUCTION}

Gravel can be found in coastal settings throughout the world, both in natural conditions and in the design of many hard beach constructions. Frequently, gravel has been used as a buffer at the toe of permanent protective structures like sea walls, groins, jetties, or breakwaters (Pilarcyzk and den Boer 1983). However, more recently gravel has made appearances as a more integral part of shoreline protection through design of dynamic gravel revetments and gravel nourishment projects (Ahrens 1990). Despite its prevalence on beaches and shorelines research on gravel beach dynamics is historically limited with the exception of a few laboratory studies (van der Meer and Pilarczyk 1986, Blewett et al. 2000 and Pedrozo-Acuña et al. 2006) and field investigations (Allan and Komar 2002 and Austin and Masselink 2006).

As a consequence of limited research, the hydrodynamics and morphodynamics of gravel beaches are poorly understood. However, the coarse grain size suggests permeability and bottom slope are important factors. In a study by Blewett et al. (2000) infiltration on gravel beaches was found to be approximately two orders of magnitude greater than on their sandy counterparts. Also with increased grain size, beach steepness often similarly increases, creating concentrated breaking in a narrow, shore parallel zone near the beach face (Baldock and Holmes 1999). The concentrated wave breaking leads to a beach characterized by swash dominated features, including a berm, beach step or terrace, and often beach cusps (Austin and Masselink 2006).

In an effort to increase understanding of gravel beach processes, the following study was proposed to investigate profile evolution both experimentally and numerically. Four tests were devised to examine the effects of incident wave conditions and initial beach geometry on a laboratory gravel beach where bedload transport was expected to dominate. The recorded hydrodynamics and profile evolution were compared with the numerical model CSHORE to evaluate bedload transport equations used within the surf and swash zones. The remaining paper discusses the experimental procedures, results, and comparisons with the numerical predictions.

\section{EXPERIMENT}

\section{Experimental Set-Up}

The experiment was performed in a 2-dimensional wave flume in the Center for Applied Coastal Research at the University of Delaware. The flume has dimensions of approximately 22.2 meters long, 0.8 meters deep and 0.6 meters wide with a gentle sloping impermeable ramp installed along the majority of the flume as shown in Figure 1. At the "beach" end of the wave flume, approximately 700 $\mathrm{kg}$ of gravel was added with a median diameter, specific gravity, fall velocity, and porosity of $2.0 \mathrm{~mm}$, $2.7,25 \mathrm{~cm} / \mathrm{s}$ and 0.4 , respectively. The constructed beach consisted of an initial beach slope of $1 / 20$, intersecting the impermeable slope and a foreshore slope of either $1 / 2$ or $1 / 5$. Four tests were performed on the different initial beach geometries and with varied incident wave heights to investigate profile change. A summary of the test conditions is provided in Table 1. Each test consisted of a series of 400 second wave bursts generated by a piston-type wave paddle according to the TMA spectrum. In each of the four tests, the wave period was kept constant with a spectral peak period, $T_{p}$ of

1 Center for Applied Coastal Research, University of Delaware, 259 Academy Street, Newark, DE, 19716, USA 
approximately 2 seconds. Two different wave heights were used in the experiment, a low spectral wave height $H_{m o}=6 \mathrm{~cm}$ and a higher wave height $H_{m o}=12 \mathrm{~cm}$. The first two tests were performed on an initially steep slope of $1 / 2$, one with the lower (test SL) and one with higher (test SH) wave height. A third test had an initially milder beach slope of $1 / 5$ with the higher wave height (test $\mathrm{MH}$ ). A fourth and final test was initiated on the final profile from test $\mathrm{MH}$ with an added nearshore bar constructed of the same gravel with an approximate cross-shore area of $515 \mathrm{~cm}^{2}$ (test MB).

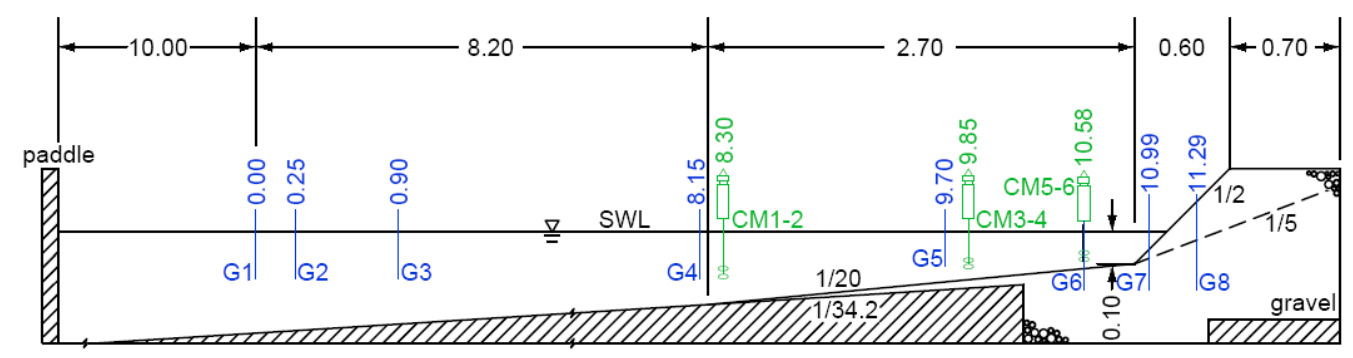

Figure 1. The experimental set-up used for each of the four tests (not to scale). Included in the figure are the wave gauge (shown in blue) and current meter (shown in green) locations, the numbers above each instrument represent the cross-shore location measured from the furthest offshore gauge G1. The bottom of the figure shows the 1/34.2 impermeable slope installed along the bottom of the wave flume.

\section{Data Collection}

Eight wave gauges (G1-G8) were used to record the instantaneous free surface elevation $\eta$, measured from the still water level (SWL), with cross-shore locations as shown in Figure 1. Each gauge recorded the entire 400 second burst duration; however, the first 40 seconds of data were removed for analysis. The three offshore gauges G1-G3 were used to separate the incident and reflected waves during each wave burst and to calculate the reflection coefficient, $R$ shown in Table 1 which summarizes the incident wave conditions for the four tests. Statistics from gauge G1 including the spectral significant wave height $H_{m o}=4 \sigma_{\eta}$ and spectral peak period $T_{p}$ were further used to represent the offshore wave conditions in the model domain. The remaining five onshore gauges were placed to measure wave shoaling, breaking, and run-up. From each wave burst, the mean and standard deviation $\sigma_{\eta}$ of the free surface and the wet probability $P_{w}$ were calculated for each gauge location. The wet probability $P_{w}$ represents the ratio of the wet duration $\left(\eta>\right.$ bottom elevation, $\left.z_{b}\right)$ to the total burst duration. In regions where the wet probability is less than $100 \%$, hydrodynamic statistics represent averaging during only the wet duration. Similarly, fluid velocity statistics including the mean and standard deviation $\sigma_{U}$ were calculated for each wave burst using current meter data collected by three pairs of electromagnetic current meters (CM1-CM6). The current meters were positioned near-to or in the same cross-shore location as three of the nearshore wave gauges, G4, G5 and G6, as illustrated in Figure 1. Finally, the profile evolution was captured by measuring the initial, final, and at least three intermediate profiles for each of the four tests. In each instance of profile measurement, three transects of the bottom elevation, $z_{b}$ were measured to ensure longshore uniformity. The three transects were averaged for analysis, they are discussed and presented in the next section.

\begin{tabular}{|c|c|c|c|c|}
\hline & & & & \\
\hline & & & I est IVIH & I est IVIB \\
\hline Foreshore slope & $1 / 2$ & $1 / 2$ & $1 / 5$ & $\sim 1 / 5$ \\
\hline $\mathrm{H}_{\mathrm{mo}}(\mathrm{cm})$ & 5.6 & 12.0 & 12.3 & 12.2 \\
\hline $\mathrm{T}_{\mathrm{p}}(\mathrm{sec})$ & 1.9 & 2.0 & 2.0 & 2.0 \\
\hline $\mathrm{H}_{\mathrm{s}}(\mathrm{cm})$ & 5.4 & 12.4 & 12.6 & 12.7 \\
\hline $\mathrm{T}_{\mathrm{s}}(\mathrm{sec})$ & 1.8 & 1.9 & 1.9 & 1.9 \\
\hline $\mathrm{R}$ & 0.35 & 0.28 & 0.26 & $0.23-0.31$ \\
\hline Number of bursts & 18 & 18 & 18 & 36 \\
\hline
\end{tabular}


Results

The hydrodynamic statistics collected during test $\mathrm{SH}$ are presented in a later section in comparison with the numerical predictions; similar data were collected for the three other tests, and can be found in a report by Hicks et al. (2010). The measured profile evolution for each of the four tests is presented in Figure 2. The two steep slope profiles showed rapid evolution to reach quasi-equilibrium conditions, demonstrated by the relatively constant profile after three wave bursts. In both steep slope tests offshore transport was observed above the still water level, creating a beach terrace just below as can been seen from approximately $x=10.5$ to $11.2 \mathrm{~m}$. The resulting profile for test SL is slightly steeper than in test SH, as highlighted in Figure 3, demonstrating the influence of wave height on the quasiequilibrium profile. Also a consequence of wave height is the deposition at the seaward edge of the horizontal berm in test $\mathrm{SH}$, observed to develop due to infiltration in the region of maximum run-up.
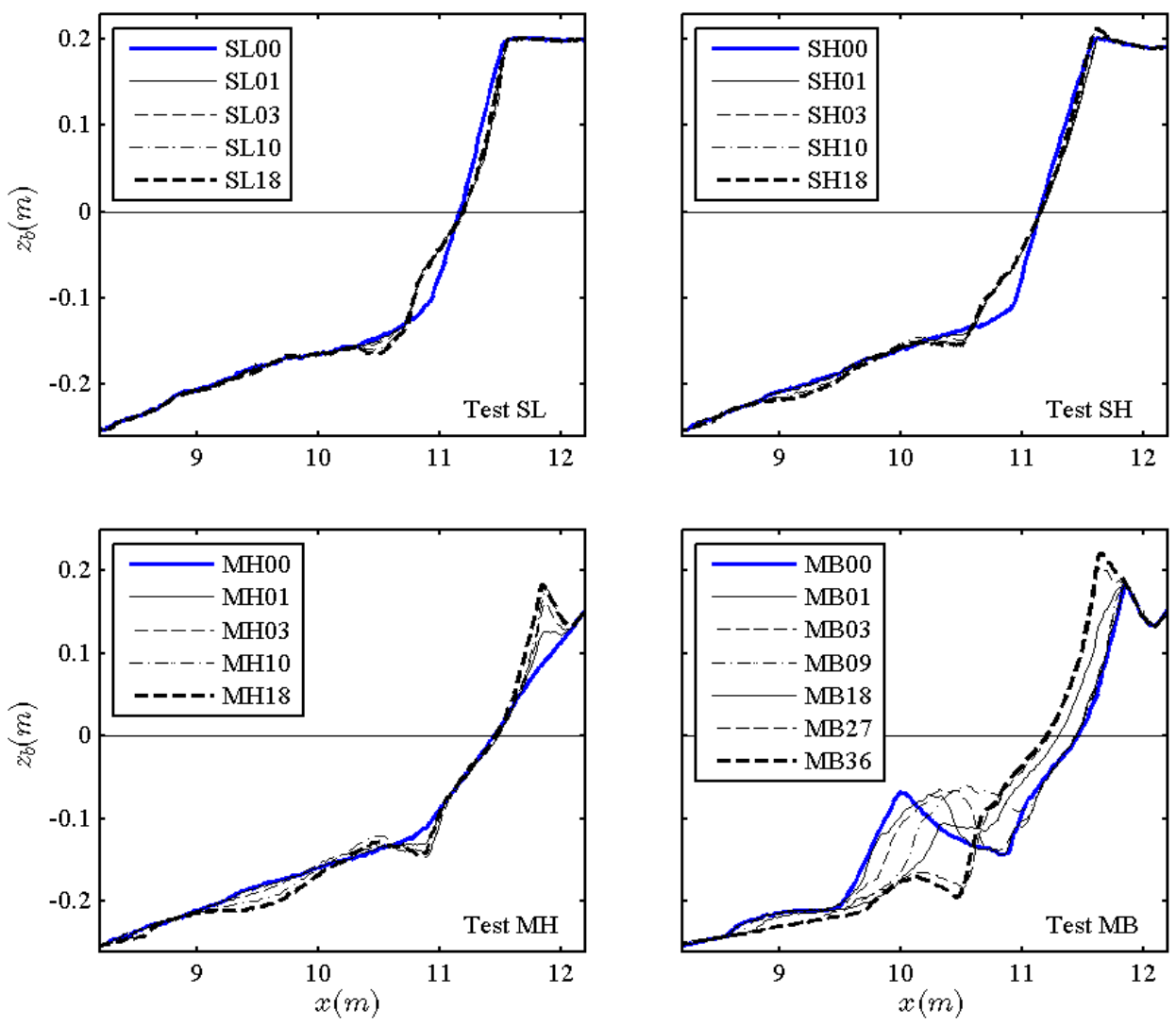

Figure 2. The measured profile evolution for tests $\mathrm{SL}, \mathrm{SH}, \mathrm{MH}$, and $\mathrm{MB}$ (clockwise from top left). The integers represent the number of wave bursts prior to the profile measurement. The cross-shore coordinate, $x$ is measured from the furthest offshore wave gauge G1 and the bed elevation $z_{b}$ is measured from the still water level.

The initially milder slope tests required considerably more time to reach quasi-equilibrium conditions, as demonstrated in the profile evolution shown in Figure 2. In both tests, steady onshore transport was observed throughout the entire gravel zone. This was demonstrated through the formation of a berm in test $\mathrm{MH}$ and the onshore bar migration followed by a seaward shift of the beach face in test MB. The final profiles from the two mild tests along with test SH can be seen in Figure 3, all of which had the same incident wave conditions. The figure shows the resulting profiles were similar within 0.4 meters (equal to approximately $3 H_{m o}$ ) of the still water level. Larger variation can be observed outside this region, likely due to the differences in initial beach geometry and test duration. In the later profiles of all four tests, an erosion zone is apparent just seaward of the beach terrace. This region was observed to develop due to eddies generated by backwash interference with incoming breaking waves. Also observed in each test was the steady onshore transport along the 1/20 slope, as evidenced by the migration of the edge of the gravel. This trend is quantified later in Table 3. 

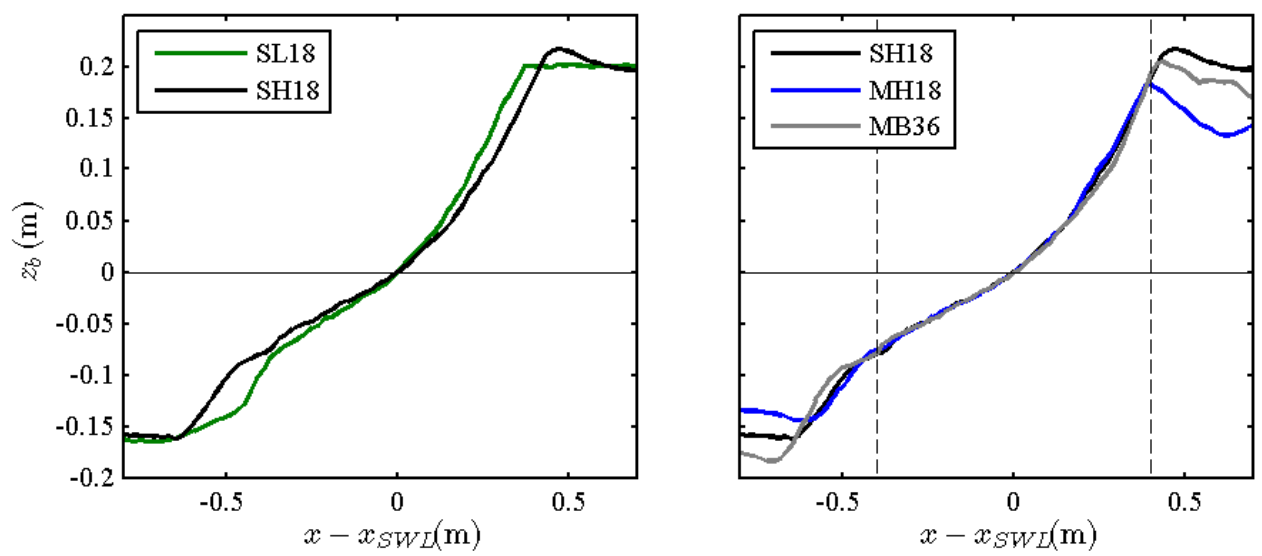

Figure 3. A comparison of the final, quasi-equilibrium profiles from the two slope steep tests (left) and the three large wave height tests (right). Each profile was realigned to a common origin using the still water shoreline position $x_{S W L}$ in each final profile.

\section{NUMERICAL MODEL CSHORE}

Details of the time- and depth-averaged numerical model CSHORE can be found in Kobayashi et al. (2010). In this study, modifications to the bedload transport formulations were made to improve prediction of profile evolution of the milder-sloped gravel beach tests. The model consists of two hydrodynamic models, the combined wave and current model used in the offshore and surf zone and the probabilistic model for the wet and dry zone. The offshore limit of the model domain is set at the furthest offshore gauge G1, where the gauge statistics are used as wave forcing conditions. From there, the model marches landward using time-averaged linear wave and current equations (Mei 1989) for continuity, momentum and wave action to predict the cross-shore variation of the mean and standard deviation of the free surface and the fluid velocity. In the wet and dry zone, the time-averaged continuity and momentum equations are derived from non-linear shallow water wave equations (Wurjanto and Kobayashi 1993). In the wet and dry region, the instantaneous water depth is assumed to have an exponential probability distribution.

The two hydrodynamic models provide the necessary predictions for the sediment transport model to estimate profile evolution based on criteria for sediment movement and suspension. The probability of movement $P_{b}$ is the same as used for a stone armor layer where movement occurs if the critical stability parameter of 0.7 is exceeded. The probability of movement is then used to predict the bedload transport rate, $q_{b}$ using the following equation

$$
q_{b}=\frac{b P_{b} G_{s} B_{r} \sigma_{U}^{3}}{g(s-1)} ; B_{r}=\frac{z_{b}-z_{p}}{d_{50}} \leq 1
$$

where $b$ is the empirical bedload parameter taken as $b=0.002, G_{s}$ is a function of the bottom slope $S_{b}$, and $B_{r}$ is a reduction factor to account for limited gravel availability, $g$ is gravitational acceleration, and $s$ is the specific gravity of the gravel. This estimation was found to be satisfactory for the steeper tests, but required modification for the milder slope tests. In the mild slope tests, the empirical bedload parameter was increased onshore of the breaking zone using the relationship

$$
b=0.002(1+8 Q)
$$

where $Q$ represents the fraction of breaking waves. The fraction of breaking waves $Q$ is equal to zero offshore and increases to 1 at the still water shoreline. As a result, $b$ increases from 0.002 to 0.018 . This modification to the bedload parameter allowed for a more accurate prediction of the volume of sediment transported onshore in tests $\mathrm{MH}$ and MB. An additional modification above the still water level was imposed to increase the landward extent of sediment deposition. In the region $x_{S W L} \leq x \leq$ $\left(x_{S W L}+3 H_{m o}\right)$, with $H_{m o}$ at $x=0$, a constant bedload transport rate of $q_{b}(x)=q_{b}\left(x_{S W L}\right)$ was used. The probability of suspension remained unchanged from other work because little sediment suspension was observed for coarse grains. 
COMPARISON WITH NUMERICAL MODEL

\section{Hydrodynamic Comparisons}

Hydrodynamic statistics were computed for the entire model domain for each wave burst. Figure 4 displays both the measured and computed cross-shore variation in the mean water level, free surface standard deviation $\sigma_{\eta}$, wet probability $P_{w}$, mean cross-shore velocity, and velocity standard deviation $\sigma_{U}$ for the 18 bursts from test SH. Similar results were obtained for the other three tests and can be found in Hicks et al. (2010). The model predictions of free surface statistics decrease in accuracy onshore, due to sensitivity to the accuracy of bed elevation predictions in the intermittently wet region. This is reflected in gauges G7 and G8 which predicted the mean and standard deviation $\sigma_{\eta}$ within $2 \mathrm{~cm}$ in comparison to the offshore gauges which predicted the statistics within $0.6 \mathrm{~cm}$. CSHORE overpredicted the cross-shore location where the wet probability $P_{w}$ dropped below $100 \%$, but still predicted wet probabilities within $12 \%$. The velocity data collected by each pair of current meters was averaged to provide a single representative velocity. However, difficulty in pinpointing an elevation to measure a depth-averaged velocity (used in CSHORE) created slightly larger discrepancies between the measured and computed velocity statistics. The mean and the standard deviation $\sigma_{U}$ were predicted within 3 and $6 \mathrm{~cm} / \mathrm{s}$, respectively. The predictions of hydrodynamic statistics are consistent with previous work done on sandy laboratory beaches.
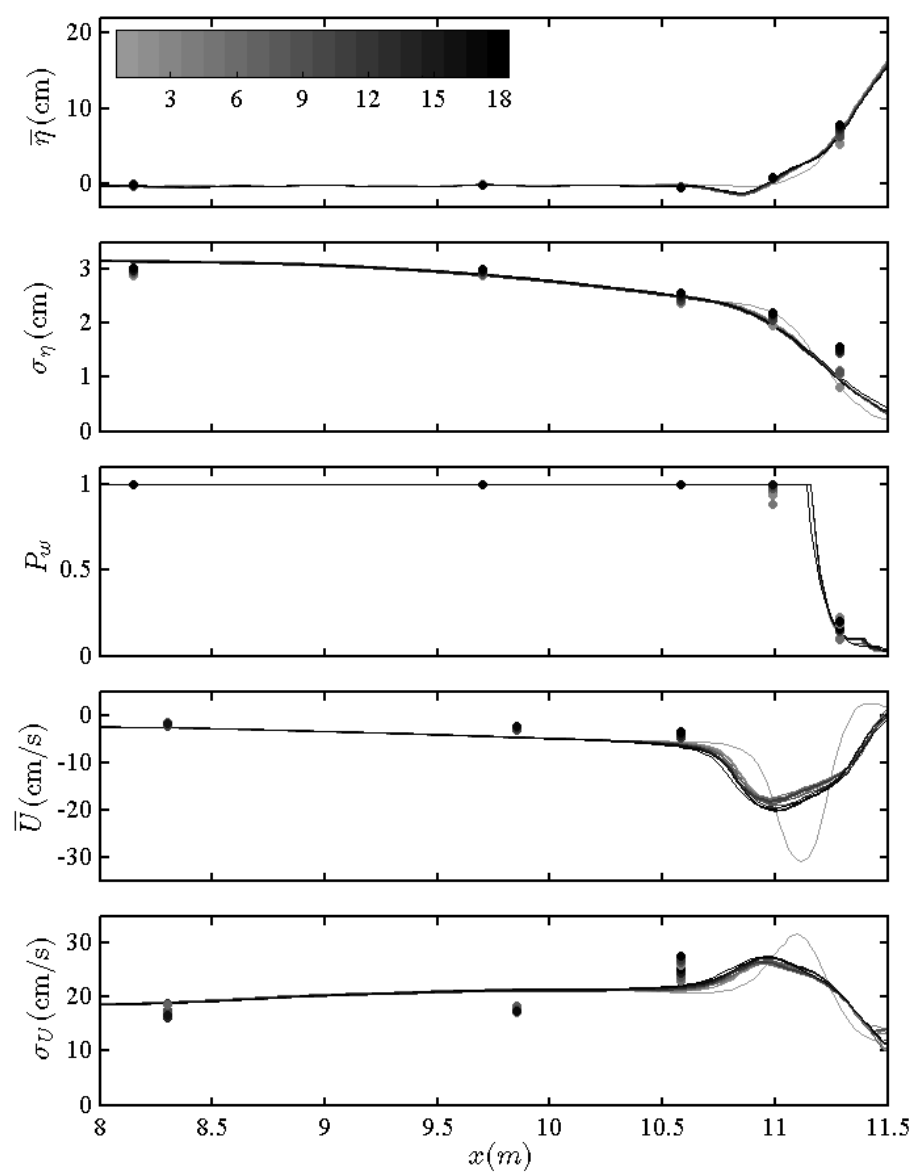

Figure 4. The comparison of experimental measurements and numerical predictions of the hydrodynamic statistics for test SH including the mean (top) and standard deviation $\sigma_{\eta}$ (second form top) of the free surface elevation, the wet probability $P_{w}$ (middle) and the mean (second from bottom) and standard deviation $\sigma_{U}$ (bottom) of the fluid velocity. The measured statistics are represented by the solid circles and the predicted values are presented by the solid lines. The color gradient corresponds to the wave burst number. NOTE: only gauges G4-G8 are presented, the statistics from offshore gauge G1 were used as model input and consequently the agreement is very good at the three gauges. 


\section{Profile Evolution}

The comparisons of the measured and predicted profile evolution for tests SL, SH, and MH are presented in Figure 5. In each of the tests, the trend of profile evolution was correctly captured, predicting erosion for the two steeper slope tests and accretion in test MH. However, there are a few shortcomings in each profile prediction. The figure shows the rate of net sediment transport for the steeper slope tests was considerably underpredicted. The quasi-equilibrium profile established by burst three during experimentation required 18 bursts in the model prediction. However, the predictions of the final profile are satisfactory, with a volumetric percent error of less than $30 \%$ in test SL and less than $60 \%$ in test $\mathrm{SH}$. The volumetric percent error was computed using the following formulation

$$
\text { volumetric \% error }=\frac{\left|V_{m}-V_{p}\right|}{\left|V_{m}\right|}
$$

where $V_{m}$ and $V_{p}$ represent the measured and predicted eroded (or accreted) volumes per unit width, respectively. The time-averaged numerical model also created a few errors in the smaller details of the final profile. The model was unable to capture the erosion zone which developed seaward of the beach terrace, most likely because a time-averaged model cannot predict the turbulent hydrodynamics that were observed in this region. Predicting the impact of infiltration on profile evolution is also a

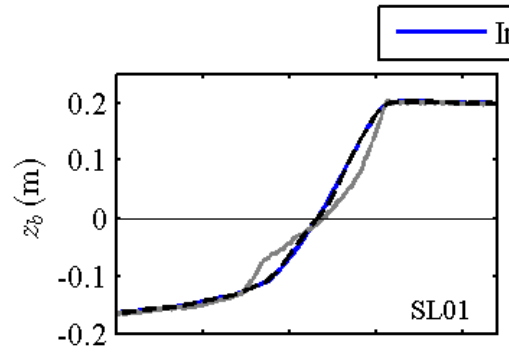

Initial $\longrightarrow$ Measured ----· Computed
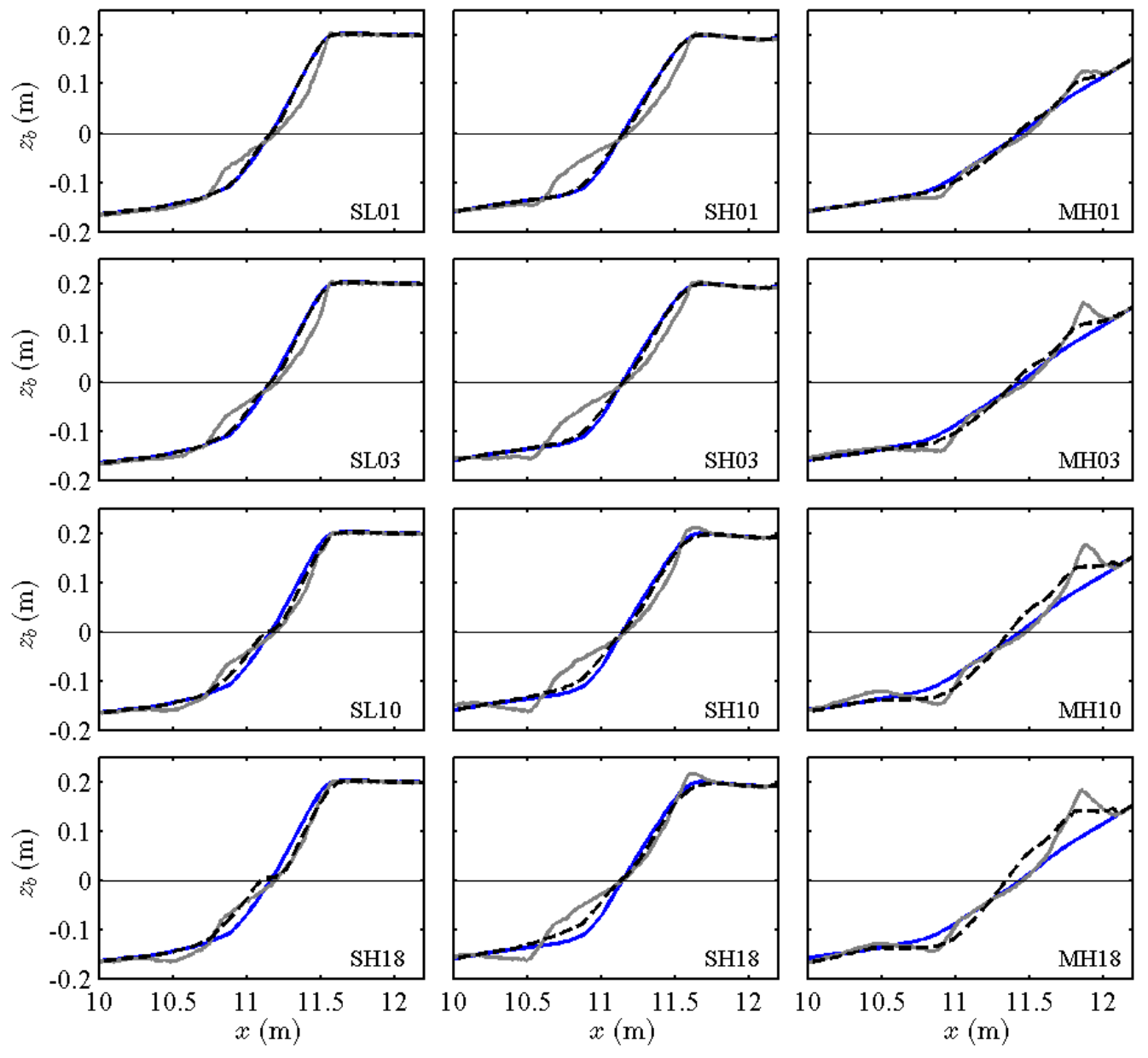

Figure 5. A comparison of the measured and computed profile evolution for tests SL (left), SH (middle), and MH (right). Each panel represents a instance of profile measurement and the corresponding predicted profile at the same time step. The test initials and burst number are included in the bottom right corner of each panel. Only profile evolution from $x=10$ to 12.2 meters is shown to highlight where the majority of profile evolution occurred. 
noticeable shortcoming of the model. The deposition at maximum uprush in test $\mathrm{SH}$ and the development of the berm in test $\mathrm{MH}$ were observed to be a consequence of infiltration at the point of maximum run-up. The sediment transport model used in CSHORE does not account for infiltration directly and instead incorporates it in the hydrodynamic models. This could account for the discrepancies in deposition prediction for tests $\mathrm{SH}$ and $\mathrm{MH}$ shown in Figure 5.

The adjustments to the bedload parameter described in the numerical model section of the paper allowed for a more accurate prediction of the bedload transport rate in the mild slope tests MH (shown in Figure 5) and MB (shown in Figure 6). The predicted volume deposited above the still water shoreline in test MH stays consistent with measurements, as demonstrated by a volumetric percent error of only $17 \%$ shown in Table 2. In test MB, the rate of transport can be observed through the onshore migration of the bar, which CSHORE predicts well as seen in Figure 6. The model also successfully predicts transition from onshore bar migration to a seaward shift of the profile through deposition of the bar material. The change in the profile evolution pattern is most easily observed in the panels for burst
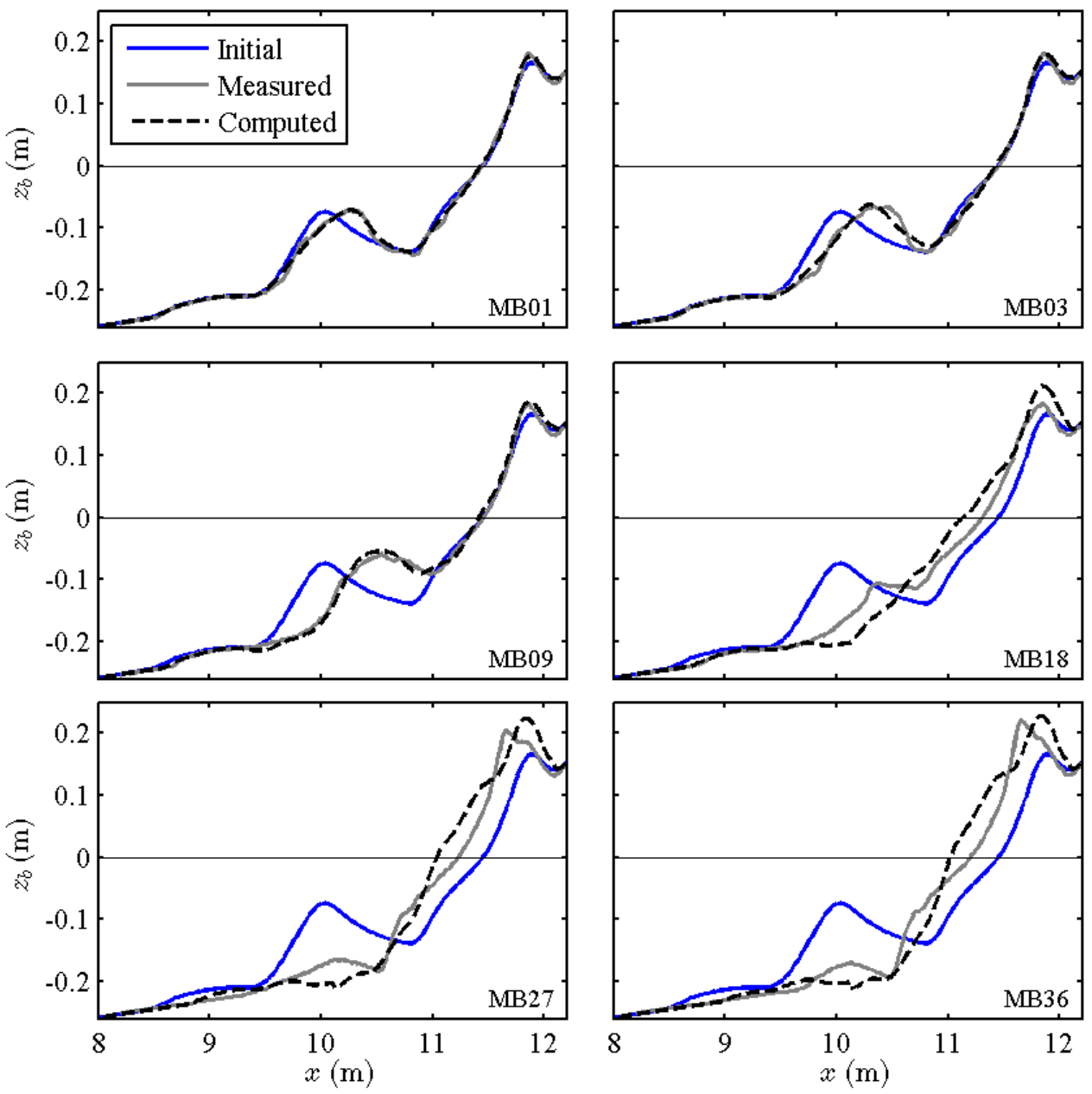

Figure 6. A comparison of the measured and computed profile evolution for test MB. Each panel represents a instance of profile measurement and the corresponding predicted profile for the time elapsed. The burst number is included in the bottom right corner of each panel.

MB09 and MB18 in Figure 6. The shape of the final predicted profile is noticeably different from the measured result largely due to the development of an extra lens of gravel just landward of the SWL. This formation is believed to be a result of the bottom slope function $G_{s}$, which trends to zero when the beach slope $S_{b}$ becomes approximately 0.3 .

A final indication of the success of the bedload transport formulations is an analysis of the steady onshore migration of the seaward edge of the gravel profile. Table 3 shows a comparison of the measured displacement of the gravel edge with the displacement predicted by CSHORE. The small 
wave conditions in test SL created little migration, which CSHORE similarly captures, predicting zero migration. The rate of migration in tests $\mathrm{SH}$ and $\mathrm{MH}$ was well predicted, within $4 \mathrm{~cm}$ for both tests. The displacement in test MB was well-predicted up to burst 18, after which the measured migration accelerated significantly, a change not captured by CSHORE.

\begin{tabular}{|c|c|c|c|c|c|c|c|c|}
\hline \multirow{3}{*}{$\begin{array}{l}\text { Burst } \\
\text { Number }\end{array}$} & \multicolumn{8}{|c|}{ Edge of Gravel Displacement [meters] } \\
\hline & \multicolumn{2}{|c|}{ Test SL } & \multicolumn{2}{|c|}{ Test SH } & \multicolumn{2}{|c|}{ Test MH } & \multicolumn{2}{|c|}{ Test MB } \\
\hline & Measured & Predicted & Measured & Predicted & Measured & Predicted & Measured & Predicted \\
\hline 00 & 0.00 & 0.00 & 0.00 & 0.00 & 0.00 & 0.00 & 0.00 & 0.00 \\
\hline 01 & 0.02 & 0.00 & 0.06 & 0.04 & 0.10 & 0.06 & 0.00 & 0.01 \\
\hline 03 & 0.03 & 0.00 & 0.10 & 0.08 & 0.14 & 0.12 & 0.00 & 0.07 \\
\hline 09 & - & - & - & - & - & - & 0.12 & 0.15 \\
\hline 10 & 0.06 & 0.00 & 0.20 & 0.16 & 0.24 & 0.26 & - & - \\
\hline 18 & 0.06 & 0.00 & 0.24 & 0.26 & 0.38 & 0.38 & 0.24 & 0.25 \\
\hline 27 & - & - & - & - & - & - & 0.92 & 0.39 \\
\hline 36 & - & - & - & - & - & - & 1.18 & 0.51 \\
\hline
\end{tabular}

\section{CONCLUSION}

Four tests on a gravel beach were completed to investigate profile evolution in comparison with the time-averaged numerical model CSHORE. The comparison allowed for a more rigorous examination of the bedload transport equations than with previous work on sandy beaches, where both suspended and bedload transport are important. In each test, onshore transport was observed across the gravel zone with an exception landward of the still water shoreline of the steep $1 / 2$ beach face. The model was shown to predict the same trends in profile evolution for both of the steep slope cases, the mild slope test, and nearshore bar test. However, an increased bedload parameter was required to increase the volume of sediment transported in the surf and swash zones in the milder test conditions. Elements of the quasi-equilibrium profiles were not captured by the model due to shortcomings in accounting for infiltration, sediment dynamics lost in time-averaging, and in the bottom slope function $G_{s}$. Future work is necessary to continue improving the bedload transport formulas for predicting gravel beach morphodynamics.

\section{ACKNOWLEDGMENTS}

This study was supported by the U.S. Army Corps of Engineers, Coastal and Hydraulic Laboratory under Contract Nos. W912HZ-10-P-0234 and W912BU-09-0023. The writers also thank Jens Figlus for his contributions to modifying the numerical model CSHORE.

\section{REFERENCES}

Ahrens, J.P. 1990. Dynamic revetments, Proceedings of $22^{\text {nd }}$ International Conference on Coastal Engineering, ASCE, 1837-1850.

Allan, J.C., and P.D. Komar. 2002. A dynamic revetment and artificial dune for shore protection, Proceedings of $28^{\text {th }}$ International Conference on Coastal Engineering, ASCE, 2044-2056.

Austin, M.J., and G. Masselink. 2006. Observations of morphological change and sediment transport on a steep gravel beach, Marine Geology, 229, 59-77.

Baldock, T.E., and P. Holmes. 1999. Simulation and prediction of swash oscillations on a steep beach, Coastal Engineering, 36, 219-242.

Blewett, J.C., P. Holmes, D. Horn. 2000. Swash hydrodynamics on sand and shingle beaches, Proceedings of $27^{\text {th }}$ International Conference on Coastal Engineering, ASCE, 597-609.

Hicks, B.S., N. Kobayashi, J. Figlus, J.A. Puleo, and A. Farhadzadeh. 2010. Cross-shore transport on gravel beaches. Research Report No. CACR-10-01, Center for Applied Coastal Research

Kobayashi, N., A. Farhadzadeh, J.A. Melby. 2010. Wave overtopping and damage progression of stone armor layer, Journal of Waterway, Port, Coastal, Ocean Engineering, 136(5).

Mei, C.C. 1989. The Applied Dynamics of Ocean Surface Waves, World Scientific, Singapore, 760 pp.

Pedrozo-Acuña, A., D. Simmonds, A.K. Otta, and A.J. Chadwick. 2006. On the cross-shore profile change of gravel beaches, Coastal Engineering, 53, 335-347. 
Pilarcyzk, K.W., and K. den Boer. 1983. Stability and profile development of coarse materials and their application in coastal engineering, Proceedings of International Conference on Coastal and Port Engineering in Developing Countries, Sri Lanka

van der Meer, J.W., and K.W. Pilarczyk. 1986. Dynamic stability of rock slopes and gravel beaches. Proceedings of $20^{\text {th }}$ International Conference on Coastal Engineering, ASCE, 1713-1726.

Wurjanto, A.. and N. Kobayashi. 1993. Irregular wave reflection and runup on permeable slopes, Journal of Waterway, Port, Coastal, Ocean Engineering, 119(5), 537 